\title{
A Cluster Design on the Influence of Energy Taxation in Shaping the New EU-28 Economic Paradigm
}

\author{
Marian Zaharia ${ }^{1, *}$, Aurelia Pătrașcu ${ }^{1}$, Manuela Rodica Gogonea ${ }^{2}$, Ana Tănăsescu ${ }^{1}$ and \\ Constanța Popescu ${ }^{3}$ \\ 1 School of Economics, Petroleum-Gas University of Ploiesti, 39 Bucuresti Blvd., Prahova 100680, Romania; \\ apatrascu@upg-ploiesti.ro (A.P.); ana.tanasescu@upg-ploiesti.ro (A.T.) \\ 2 Department of Statistics and Econometrics, Bucharest University of Economic Studies, 15-17 Dorobanti St., \\ Sector 1, Bucharest 010552, Romania; manuela.gogonea@gmail.com \\ 3 Faculty of Economics, Valahia University of Targoviste, Aleea Sinaia Street, No. 13, Targoviste, \\ Dambovita 130004, Romania; tantapop@yahoo.com \\ * Correspondence: marianzaharia53@gmail.com; Tel.: +40-744654830
}

Academic Editor: Jovan Zubović

Received: 4 December 2016; Accepted: 15 February 2017; Published: 21 February 2017

\begin{abstract}
Environmental and energy taxation are essential components for designing global economic policies and they often contribute to achieving the sustainable economic development goals in contemporary economies. Starting from the analysis of certain elements such as the share of environmental, energy, transport and pollution taxation in GDP and using the Hierarchical Clustering methodology, the paper aims to identify economic models of behaviour and to understand the influence of energy taxation in designing an economic paradigm. In addition, another objective of the paper is to deepen the relationships that energy taxation has in designing certain economic models of behaviour and to group the EU-28 Member States based on the specified criteria. The research results confirm that at the EU-28 level could exist elements for achieving energy taxation convergence and that the states should promote a more accurate fiscal policy in order to improve the loss of competitivity caused by an inaccurate energy taxation.
\end{abstract}

Keywords: environmental taxation; energy tax policy; energy taxes; cluster analysis

\section{Introduction}

In highly competitive and functional economies, taxation, including on energy, is an economic instrument that mobilizes resources and guides the economic behaviour to those areas that are validated as being economically competitive. Energy taxation has a multilevel influence on the economy. The energy production and consumption patterns are determinant in developing the domestic economic paradigm and they shape the economic efficiency and levels of competitiveness. In this context, the attempt to identify functional models of reference in terms of energy taxation functionality [1,2], to validate those areas economically competitive and with maximum influences in capitalization of resources has generated a classification of states, sometimes spontaneous, in clusters validated as models of efficiency on energy taxation. Also, the intensity of the energy taxation has a major impact on the real movements of the capitals and production factors that may trigger a tax competition between the EU-28 Member States.

Fiscal policy is often considered in the literature as one of the major factors for assessing the economic efficacy criteria, for promoting and developing certain industrial segments or activities, as well as for technological progress or changing the actual production paradigms [3-5]. Energy taxation shapes the industrial framework and consumption patterns that promote positive industrial changes and anticipate the ratio between the estimated opportunity cost and energy consumption. 
In [6] it is argued that environmental taxation, including the energy taxation, has a decisive influence on economic development, especially in transition economies, where directly determines the well-being standards of the society, the production technologies and the shape of the inland economic structures.

Energy taxation can be used both as an important tool to mitigate environmental problems such as pollution and climate change and as an efficient mechanism for stimulating environmentally friendly technologies, production systems with lower energy consumption and green investments. Energy taxation becomes a tool for promoting green economic development and technologies with lower greenhouse emissions. Fiscal policy in the energy field, in the EU-28, is under a comprehensive process of reconsideration and significant transformation both in terms of fiscal philosophy and the negative effects that it can generate if not reconsidered [7,8]. Because at the EU-28 Member States level there is a need to review energy taxation and transform it into a tool with multiple uses in promoting economic growth, a rethinking of the entire fiscal regime was undertaken. This rethinking was targeted especially on prices, energy consumption patterns, technological progress promotion, implementation of new energy efficient and less polluting technologies, as well as on environmental policy [9].

The high pressure of energy taxation, that also includes taxes on energy production and consumption, has contributed to the increase of the signals transmitted at the price level by high taxation on fuel. This acts as a background to the unavoidable shortages and restrictions in the supply of energy, as well as on potential energy crises, ensuring, in this context, on the one hand the movement of investments to the energy field [10,11], and, on the other hand, amplifying the efforts for saving energy and identification of new energy sources. Despite the fact that the EU-28 Member States have maintained their political option to intervene in determining the energy taxation level, the energy taxation is a determinant component in establishing the final merchandise prices and it contributes to the current market fragmentation tendency. As argued in [12], the taxation level, including energy taxes, varies considerably among the EU-28, from one state to another and some countries impose higher taxes as a result of their environmental policy, while others grant substantial subsidies. Thus, some authors emphasize the importance of fuel taxes in designing the general framework of the energy taxation system [13-15]. For example, some authors [15] emphasize the long-term positive effect of fuel taxes in Europe and argue that the carbon emissions are reduced by more than half (the content of carbon in the atmosphere is reduced by more than $1 \mathrm{ppm}$ ), by introducing high fuel taxes. This situation is also confirmed by a study on highly intensity energy consumption, as this research [16] explains the importance of increasing fuel taxes in order to respond to the rapid increase of motor vehicles number and energy demand in China. Other authors [14] have reached the same conclusion after they used an EDC model to evaluate the impact of various tax scenarios for China.

Returning to the Europe, fiscal policy in the EU-28 energy field cannot be limited only to the economic effects of incomes that are generated by the implementation of such a policy both at member state or at a European level and also cannot be understood as just an academic exercise [7-18].

In the literature there are some studies on the role of energy taxation in directing economic resources to those industries with high efficiency technological and production processes. In [19], it is claimed that environmental taxation can be a more effective tool in promoting economic growth if it is accompanied by a state support system for energy-efficient areas. Also, in [20], a European energy policy review concluded that there is a contradiction regarding the energy tax system and tax incentives that significantly influences the competitiveness of European industry. Some authors [21] have analysed the political economy determinants of energy tax differentiation, especially across industrial sectors.

From an extensive approach, the EU-28 energy tax policy [22-26] combines the elements of a free market approach, governed by free and optimum allocation of energy resources with regulations sanctioning energy intensive consumers. States are free to choose what system of energy taxation to use, how they will use it and whether it contributes to reducing greenhouse gases. At the EU-28 level, member states should use the least expensive way to comply with regulations on taxation in conditions 
of increasing the productivity gaps generated both at the taxation and environmental regulations levels. Therefore, the main role of energy tax policy is, on the one hand, to create incentives to reduce the additional consumption cost of energy resources and, on the other hand, to stimulate the introduction of new production technologies.

The research and results presented in this paper started from some observations that are further described in the following paragraphs. Firstly, in 2002, the total environmental taxes as a percentage of GDP varied between a minimum value of $2.0 \%$ in Estonia and a maximum value of $4.8 \%$ in Denmark, the difference thus being of $2.8 \%$ percentage points. In this interval, the 30 states that are analysed in terms of total environmental taxes as a \% of GDP were grouped as follows: in two states levels higher than $4 \%$ were recorded, in seven states the total environmental taxes as a $\%$ of GDP were between $3.0 \%$ and $3.9 \%$ and in the other 21 states the indicator varied between $2.0 \%$ and $9.9 \%$. Secondly, in 2012 , the total environmental taxes as a \% of GDP ranged between a minimum value of $1.6 \%$ in Spain and a maximum value of $3.9 \%$ in Denmark, the difference decreasing to only 2.3 percentage points. Besides the decrease in the difference between the highest level and the lowest level of the total environmental taxes as a \% of GDP that were recorded in the 30 states, a shift of those states from higher levels to lower levels of total environmental taxes as a \% of GDP had occurred. Thus, in 2012, in seven states the level of the total environmental taxes as a \% of GDP was between $3.0 \%$ and $3.9 \%$, in 18 states this indicator fell in an interval of $2.0 \%$ and $2.9 \%$ and in five states this indicator varied between $1.6 \%$ and $1.9 \%$.

Taking into account these considerations, as well as the fact that the total environmental taxes include energy taxes (including taxes for transport fuel), transport taxes (excluding taxes for transport fuel) and pollution taxes, the paper emphasizes the changes recorded regarding the aggregated levels of those indicators in groups of states in 2012 in comparison with 2002.

In this context, the main objectives of this research are focused on two main directions. The first objective is to identify the structural shifts that occurred over a period of 10 years (2002-2012) in the fiscal policy including energy taxation, evidenced by the restructuring of groups of states. The second one targets the possible existence of a convergence of the energy taxation policy among the 30 states that are analysed by taking into consideration four relevant variables that are statistically significant and prove the high influence on fiscal policy establishment.

\section{Research Methodology}

The research instrument employed in this article is the Hierarchical Clustering methodology that is used to identify economic models of behaviour among the EU-28 Member States and to emphasize the influence of energy taxation in designing a fiscal convergence model. Hierarchical Clustering discovers successive clusters using previously established clusters, so this methodology builds a group hierarchy (dendrogram) and not just a simple object partition [27].

This methodology was used in order to obtain groups that are significant in terms of the analysed indicators because it is a robust methodology, it has a very high level of applicability in this type of studies and its stages are graphically emphasized by a dendrogram. It allowed us to generate and combine those 30 states in clusters by homogeneity criteria, in terms of the indicators that are analysed based on certain levels of the Total Sum of Squared Error. These levels are used to identify the optimum number of clusters that ensure conclusive and statistically significant values of the means recorded for groups of states.

In order to achieve the research goals, the authors choose to group the economic criteria of all the EU-28 Members States, as well as Norway and Iceland using four distinct variables (Table 1) that offer a relevant image of the countries' grouping in terms of energy taxation policy. 
Table 1. Description of variables.

\begin{tabular}{cc}
\hline Variable & Description \\
\hline ENV_GDP & Total environmental taxes as \% to GDP \\
ENG_GDP & Energy taxes (including taxes for transport fuel) as \% to GDP \\
TRS_GDP & Transport taxes (excluding taxes for transport fuel) as \% to GDP \\
$P O L \_G D P$ & Pollution taxes as \% to GDP \\
\hline & Source: the authors' own selection based on [22,28].
\end{tabular}

As stated above, the main analysis methodology used to group the 30 States (EU-28, Norway and Iceland), included in the analysis, based on the share of environmental, energy, transport and pollution taxes in GDP was the Hierarchical Clustering methodology, starting from a matrix function such as:

$$
Y=\left\|y_{i j}\right\|_{i=\overline{1, n}, j=\overline{1, m}}
$$

where $n$ constitutes the number of states subject to the analysis and $m$ constitutes the number of indicators taken into account for determining clusters. On the elements of matrix $Y$, we applied the following transformation:

$$
z_{i j}=\frac{y_{i j}-\bar{y}_{j}}{\sigma_{j}}, \quad \text { where } \quad \bar{y}_{j}=\frac{\sum_{i=1}^{n} y_{i j}}{n}, \quad \sigma_{j}=\sqrt{\frac{\sum_{i=1}^{n}\left(y_{i j}-\bar{y}_{j}\right)^{2}}{n-1}}
$$

By using (2) and Euclidian distance [29], the Proximity Matrix was obtained:

$$
W=\left\|w_{i j}\right\|_{i=\overline{1, n}, j=\overline{1, m}}, \quad w_{i j}=\sqrt{\sum_{i=1}^{n}\left(z_{i k}-z_{i j}\right)^{2}}, j=\overline{1, m}, k=\overline{1, m} j \neq i, k \neq i, w_{i i}=0
$$

In order to determine the distance between clusters, Ward's method was used. Being two clusters $A$ and $B$ and $x_{i}$ an item (a cluster or an individual element, not included yet in a cluster) to include in a cluster, the distance between cluster A and cluster B is defined as follows [30]:

$$
\Delta(A, B)=\sum_{i \in A \cup B}\left\|x_{i}-m_{A \cup B}\right\|^{2}-\sum_{i \in A}\left\|x_{i}-m_{A}\right\|^{2}-\sum_{i \in B}\left\|x_{i}-m_{B}\right\|^{2}-\frac{n_{A \cap B}}{n_{A \cup B}}\left\|m_{A}-m_{B}\right\|^{2}
$$

In (4), $m_{i}$ is the centroid and $n_{i}$ is the number of elements from cluster $i$.

We started by searching for the best solution to validate the structure of the clusters. In order to do so, the values of Total Sum of Squared Error (TSSE) were determined for each possible solution, containing $n>2$ clusters. For a solution with $n$ clusters, in which $y_{k i j}$ is the value of the element $i j$ from the cluster $k$ and $\bar{y}_{k i}$ is the mean of the variable $i$ from the cluster $k$, TSSE is:

$$
\operatorname{TSSE}_{n}=\sum_{k=1}^{n} \sum_{i=1}^{r} \sum_{j=1}^{m_{i}}\left(y_{k i j}-\bar{y}_{k i}\right)^{2},
$$

When $n$ increases, $T S S E_{n}$ is reduced as the number of elements in the clusters is gradually becoming smaller. Starting from this observation, "an appropriate cluster solution could be defined as the solution at which the reduction in SSE slows dramatically" [31].

Testing the significance of belonging of a variable to clusters was mainly achieved with the Analysis of Variance (ANOVA) methodology. We have noted with $r \geq 2$ the number of variables considered for generating the clusters and with $n_{i}$ the number of elements from the data series corresponding to variable $i$. Thus, the tested hypotheses are: 
$\mathrm{H}_{0 \_1}$ : there is no significant difference between the means of the analysed variables (the analysed variable's belonging to the clusters is not statistically significant):

$$
F_{\text {stat }}=\frac{\sum_{i=1}^{r}\left(\bar{y}_{i}-\bar{y}_{0}\right)^{2} n_{i} / d f_{1}}{\sum_{i=1}^{r} \sum_{j=1}^{n i}\left(y_{i j}-\bar{y}_{i}\right)^{2} / d f_{2}}<F_{\alpha, r-1, n-r},
$$

$\mathrm{H}_{1 \_1}$ : there is a significant difference between the means of the analysed variables (the analysed variable's belonging to the clusters is statistically significant):

$$
F_{\text {stat }}>F_{\alpha, r-1, n-r} \text { equivalent to Sign. } F<\alpha,
$$

The application of the ANOVA methodology is conclusive if there is no significant difference between the variances of the data series corresponding to the analysed variables. The test's hypotheses are:

$\mathrm{H}_{0 \_} 2$ : there are no significant differences between the values of the variances:

$$
\sigma_{1}^{2}=\sigma_{2}^{2}=\sigma_{3}^{2}=\ldots=\sigma_{r}^{2}
$$

$\mathrm{H}_{1 \_2}$ : There are significant differences between the values of the variances $\left(\exists \sigma_{i}^{2} \neq \sigma_{j}^{2}\right)$.

To test the null hypothesis, the Levene's Test was employed, which uses the absolute value of the residuals and checks, using ANOVA, if between the means of these exist significant differences. The condition of accepting the null hypothesis is:

$$
\text { Sign.F }>\alpha \text { equivalent to } F_{\text {stat }}<F_{\alpha, r-1, n-r},
$$

If the null hypothesis $\mathrm{H}_{0 \_2}(8)$ is rejected, then for testing the significance of a variable's belonging to the cluster, instead of the ANOVA methodology, the Welch's Test was used [32]. The hypotheses' formulation is similar to hypotheses $\mathrm{H}_{0 \_}$and $\mathrm{H}_{1 \_}$, however the method of determining $F$ statistics is different.

$\mathrm{H}_{0 \_3}$ : there is no significant difference between the means of the analysed variables (the variable's belonging to the cluster is not statistically significant):

$$
F_{w_{-} \text {stat }}<F_{\alpha, d f_{1}, d f_{2}} \text { equivalent to Sign. } F>\alpha,
$$

$\mathrm{H}_{1 \_3}$ : there is a significant difference between the means of the analysed variables (the variable's belonging to the cluster is statistically significant)

$$
F_{w \_s t a t}>F_{\alpha, d f_{1}, d f_{2}} \text { equivalent to } \operatorname{Sign.F}<\alpha,
$$

In Equations (10) and (11):

$$
\begin{gathered}
F_{\text {stat }}=\frac{\frac{1}{r-1} \sum_{i=1}^{r} w_{i}\left(\bar{y}_{i}-\bar{y}^{\prime}\right)^{2}}{1+\frac{2(r-2)}{r^{2}-1} \sum_{i=1}^{r}\left(\frac{1}{n_{j}-1}\right)\left(1-\frac{w w_{i}}{w}\right)^{2}}<F_{\alpha, d f_{1}, d f_{2}, \quad \text { where }} \\
w_{i}=\frac{n_{i}}{s_{i}^{2}} \quad w=\sum_{i=1}^{r} w_{i} \quad \bar{y}^{\prime}=\frac{\sum_{i=1}^{r} w_{i} \bar{y}_{i}}{w} \quad d f_{1}=r-1 \quad d f_{2}=\frac{k^{2}-1}{3 \sum_{i=1}^{r}\left(\frac{1}{n_{j}-1}\right)\left(1-\frac{w i}{w}\right)^{2}}
\end{gathered}
$$

The used tools were SPSS [33] and Excel with Real Statistic Resource Pack [32]. 


\section{Results and Discussions}

By applying the methodology described in Section 2, we aim to emphasize, on the one hand, the way the 30 states have migrated from one group to another in terms of the values of the four indicators (total environmental taxes as a percentage of GDP, energy taxes as a percentage of GDP, transport taxes as a percentage of GDP, pollution taxes as a percentage of GDP) and, on the other hand, the way the mean values recorded at groups of states level in 2012 by comparison with 2002 have evolved.

The application of the methodology has imposed the classifications of EU-28 Member States, as well as Iceland and Norway in clusters on the basis of the described research criteria. Thus, based on the shares of the environmental, energy, transport and pollution taxes in GDP [22], Figure 1 presents the dendrogram for 2002 obtained using Euclidian distance (3) and Ward's method. This suggests solutions with a number of 3 to 10 clusters (or even more).

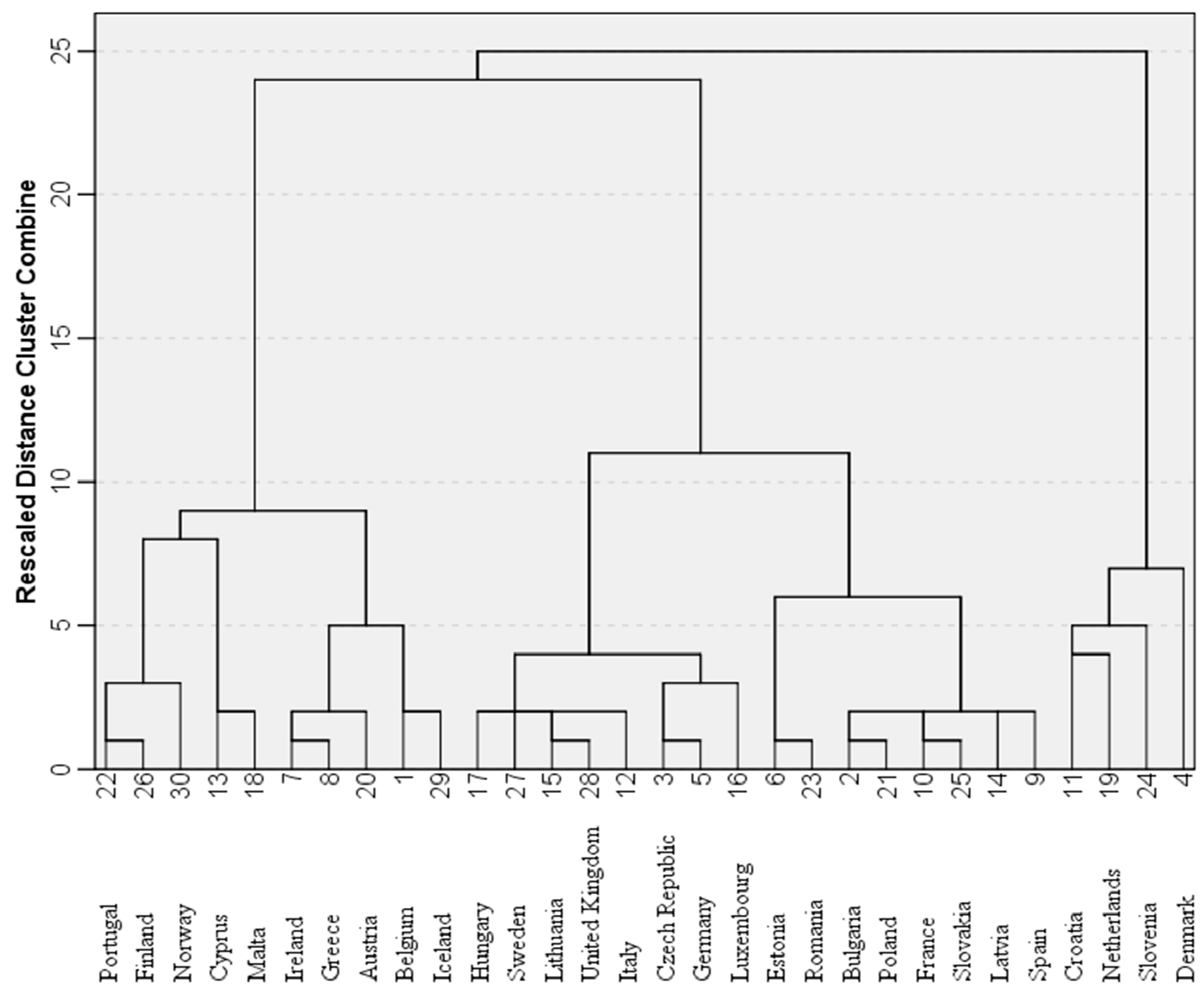

Figure 1. Dendrogram using the Ward linkage method.

Considering the evolutions of values of TSSE based on the number of clusters, presented in Figure 2, an optimal solution can be the one with seven clusters. Of the seven clusters (Table 2), clusters $\mathrm{C} 4$ and $\mathrm{C} 5$ contain eight states, cluster $\mathrm{C} 3$ includes five states, clusters $\mathrm{C} 1$ and $\mathrm{C} 6$ have three states, cluster C2 contains two states and cluster C7 includes one state (Denmark). The cluster C7 presents certain particularities at this level of confidence that separate it from the rest of the clusters.

A first step of testing the statistical validity of the chosen solution is testing the hypothesis $\left(\mathrm{H}_{0 \_} 2\right)$ regarding the inexistence of some significant differences between the variances of data series for the six clusters that contain more than one element. 


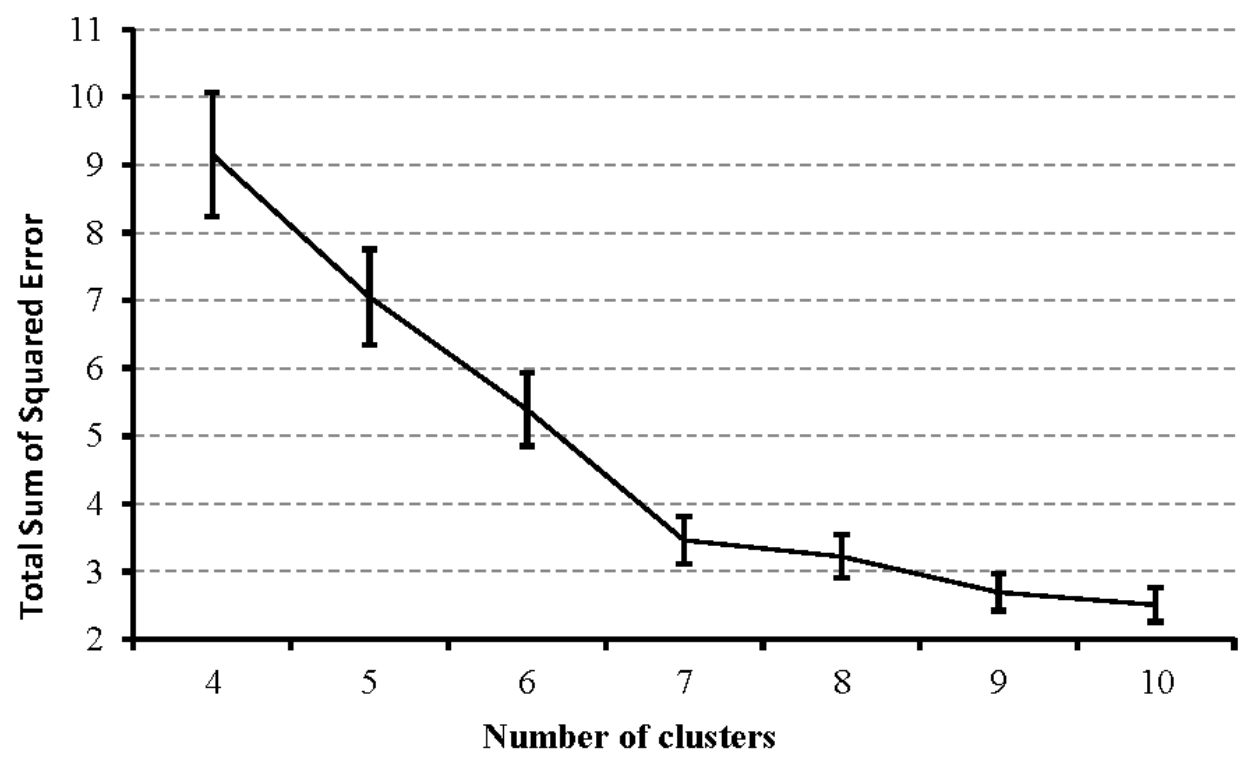

Figure 2. Number of clusters.

Table 2. The structure of the clusters determined by ENV_GDP, ENG_GDP, TRS_GDP and POL_GDP, in the year 2002.

\begin{tabular}{cl}
\hline Cluster & \multicolumn{1}{c}{ Countries Included in Clusters } \\
\hline C1 & Portugal, Finland, Norway \\
C2 & Cyprus, Malta \\
C3 & Belgium, Ireland, Greece, Austria, Iceland \\
C4 & Czech Republic, Germany, Italy, Lithuania, Luxembourg, Hungary, Sweden, United Kingdom \\
C5 & Bulgaria, Estonia, Spain, France, Latvia, Poland, Romania, Slovakia \\
C6 & Croatia, Netherlands, Slovenia \\
C7 & Denmark \\
\hline
\end{tabular}

Source: the authors' design.

The results of the Test for Homogeneity of Variance are presented in Table 3. As it can be observed, all Levene Statistic values are lower than the critical value $\mathrm{F}_{0.05,5,23}=2.64$. This observation leads to accepting the null hypothesis $\left(\mathrm{H}_{0 \_} 2\right)$ : there is no significant difference between the variances values of the data series corresponding to the clusters.

Table 3. Test for Homogeneity of Variances.

\begin{tabular}{ccccc}
\hline Variable & Levene Statistic & df1 & df2 & Sign. \\
\hline ENV_GDP & 2.211 & 5 & 23 & 0.088 \\
ENG_GDP & 1.801 & 5 & 23 & 0.152 \\
TRS_GDP & 1.713 & 5 & 23 & 0.172 \\
POL_GDP & 1.491 & 5 & 23 & 0.231 \\
\hline
\end{tabular}

Source: the authors' calculations using SPSS.

Considering that the condition $\left(\mathrm{H}_{0 \_2}\right)$ regarding the application of the ANOVA methodology is satisfied, this was used to verify the statistical significance of those four analysed variables' belonging to the clusters. The results are presented in Table 4. The values of F statistics (12) are higher than the critical value $\mathrm{F}_{0.05,6,23}=2.53$. As a consequence, the null hypothesis $\left(\mathrm{H}_{0 \_}\right)$is rejected for all four variables, while the alternative hypothesis is accepted $\left(\mathrm{H}_{1 \_3}\right)$ : the analysed variables are statistically significant considering the belonging to clusters. 
Table 4. ANOVA results for the solution with seven clusters.

\begin{tabular}{cccc}
\hline Variable & $\mathbf{F}_{\mathbf{0 . 0 5 , 6 , 2 3}}$ & $\mathbf{F}$ & Significance (Sign.) \\
\hline ENV_GDP & 2.53 & 43.729 & 0.000 \\
ENG_GDP & 2.53 & 12.984 & 0.000 \\
TRS_GDP & 2.53 & 34.004 & 0.000 \\
POL_GDP & 2.53 & 7.861 & 0.000 \\
\hline \multicolumn{5}{c}{ Source: the authors' calculations using SPSS. }
\end{tabular}

The values of the means for the analysed variables and their $95 \%$ Confidence Interval for Mean are presented in Table 5. The parameters LB and UB are Lower Bound and Upper Bound of 95\% Confidence Interval for Mean.

Table 5. The values of clusters centre (Means) for the variables ENV_GDP, ENG_GDP, TRS_GDP and POL_GDF in the year 2002 and their 95\% Confidence Interval for Mean.

\begin{tabular}{|c|c|c|c|c|c|c|c|c|c|c|c|c|c|}
\hline \multirow{2}{*}{$\mathrm{C}$} & \multirow{2}{*}{$\mathbf{N}$} & \multicolumn{3}{|c|}{ ENV_GDP } & \multicolumn{3}{|c|}{ ENG_GDP } & \multicolumn{3}{|c|}{ TRS_GDP } & \multicolumn{3}{|c|}{ POL_GDP } \\
\hline & & Mean & SD & SE & Mean & SD & SE & Mean & SD & SE & Mean & SD & SE \\
\hline $\mathrm{C}_{2002}$ & 3 & 3.13 & 0.15 & 0.09 & 1.97 & 0.15 & 0.09 & 1.13 & 0.23 & 0.13 & 0.03 & 0.06 & 0.03 \\
\hline $\mathrm{C} 2_{2002}$ & 2 & 3.15 & 0.21 & 0.15 & 1.15 & 0.21 & 0.15 & 1.95 & 0.07 & 0.05 & 0.05 & 0.07 & 0.05 \\
\hline $\mathrm{C}_{2002}$ & 5 & 2.42 & 0.16 & 0.07 & 1.34 & 0.29 & 0.13 & 0.98 & 0.16 & 0.07 & 0.08 & 0.11 & 0.05 \\
\hline $\mathrm{C} 4_{2002}$ & 8 & 2.73 & 0.18 & 0.06 & 2.24 & 0.19 & 0.07 & 0.40 & 0.20 & 0.07 & 0.06 & 0.07 & 0.03 \\
\hline $\mathrm{C} 5_{2002}$ & 8 & 2.19 & 0.14 & 0.05 & 1.80 & 0.19 & 0.07 & 0.24 & 0.11 & 0.04 & 0.15 & 0.11 & 0.04 \\
\hline $\mathrm{C} 6_{2002}$ & 3 & 3.63 & 0.42 & 0.24 & 2.37 & 0.49 & 0.28 & 0.80 & 0.40 & 0.23 & 0.47 & 0.15 & 0.09 \\
\hline $\mathrm{C}_{2002}$ & 1 & 4.80 & & & 2.60 & & & 1.90 & & & 0.30 & & \\
\hline
\end{tabular}

The detailed analysis of the results presented in Table 5 was achieved for the year 2002 and treats all the countries composing the clusters for which the evolution levels of the four variables are studied and compared: ENV_GDP, ENG_GDP, TRS_GDP, POL_GDP.

Considering the means of the variables ENV_GDP, ENG_GDP, TRS_GDP and POL_GDP, a graphic representation (Figure 3) was made for a clearer emphasizing of their evolution on clusters.

During the analysed period, all the EU-28 member states experienced, to a greater or lesser extent, the challenges generated by the economic crisis, domestic economic instability and increased dependence on energy imports to which was added a serious slowdown in economic growth. The evolution of the energy taxation is the result of both domestic and EU-28 economic paradigm changes. This paradigm change has contributed to "green" the economy and to support the economic recovery. Cluster $1\left(\mathrm{C}_{2002}\right)$, in 2002, comprises three countries: Portugal, Finland and Norway. Thus, for that year, the mean percentage value of 3.13\% per country of ENV_GDP for this cluster is the highest compared to the other three variables (ENG_GDP, TRS_GDP, POL_GDP). The percentage value is between a minimum of $3.00 \%$ for Portugal and a maximum of $3.3 \%$ in Norway, while Finland has a value of $3.1 \%$. In this case, the confidence probability of the results is $95 \%$ for a confidence interval that is between $2.75 \%$ and $3.51 \%$.

There is a reversing of the hierarchy between Portugal and Norway regarding variable ENG_GDP. The minimum percentage is $1.80 \%$ in Norway and the maximum is $3.10 \%$ for Portugal. The mean percentage value of ENG_GDP is registered in 2002, for cluster 1, at $1.97 \%$ per country.

The hierarchy of the three countries is identical for the last two variables (TRS_GDP, POL_GDP). Portugal and Finland have minimum percentage values (1.0\% at TRS_GDP and 0.00 at POL_GDP, indicating their inexistence), while Norway has a maximum percentage value of $1.4 \%$ for TRS_GDP and for POL_GDP the maximum percentage value is $0.1 \%$. The mean percentages for cluster 1 , in 2002, for these two variables are $1.13 \%$ per country for TRS_GDP and $0.03 \%$ per country for POL_GDP. 


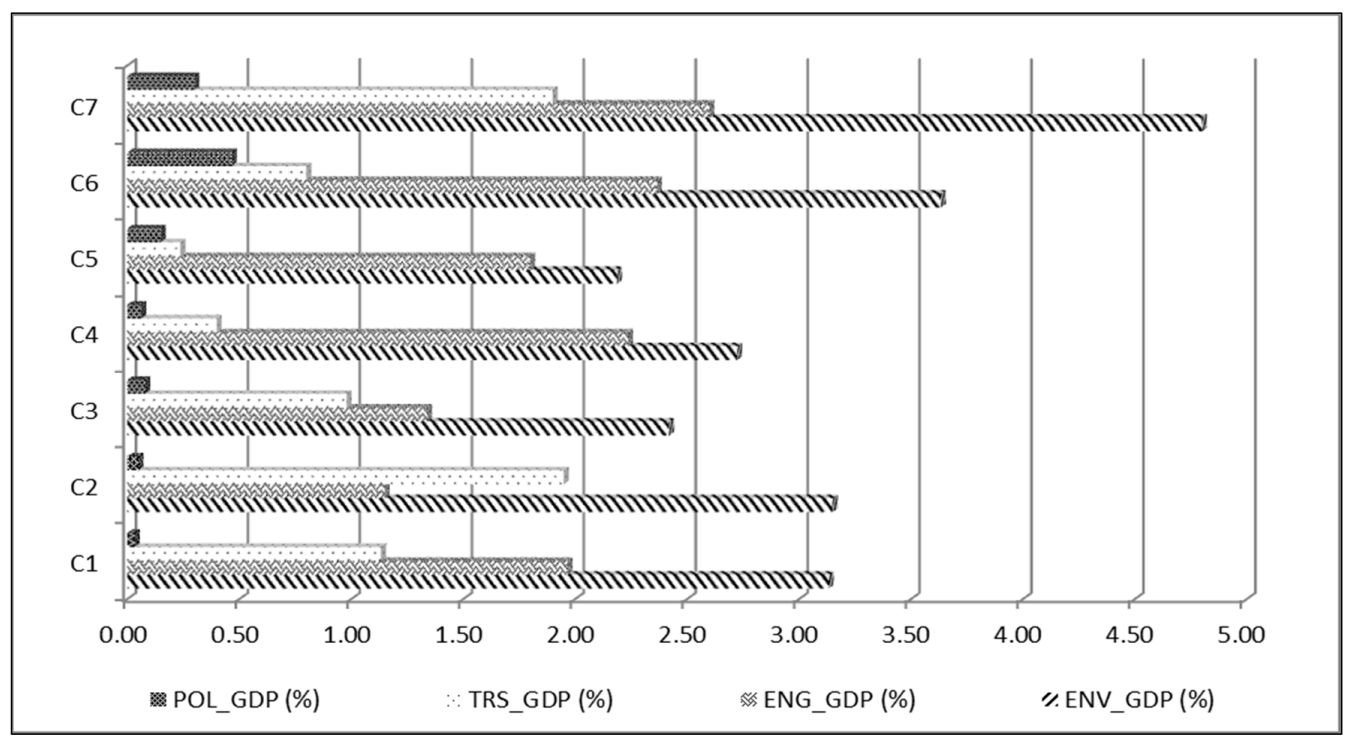

Figure 3. Evolution of ENV_GDP, ENG_GDP, TRS_GDP, POL_GDP on clusters, for 2002.

The application of the Hierarchical Clustering methodology shows us that the states could be grouped as components of traditional economic models. Both the energy fiscal policy and the environmental policy could be considered tools that can be used to design a convergence model for the EU-28 Member States. The efficiency of the energy taxation policy has represented, in 2002, a major discussion topic imposed by the necessity of increasing of the energy security and, also, by the necessity of decreasing of the supplementary costs associated to energy consumption. The energy taxation system has dramatically modelled the future economic development of the EU, by influencing the economic competitiveness.

In 2002, cluster $2\left(\mathrm{C}_{2002}\right)$ includes two countries: Cyprus and Malta. For these two countries, the mean percentage values of the four analysed variables are quite similar to the ones presented in cluster 1 . Thus, compared to the first cluster, the mean percentage is higher with 0.02 percentage points per country for ENV_GDP and POL_GDP and with 0.82 percentage points per country for TRS_GDP. The same difference of 0.82 percentage points was established between the mean percentage value for variable ENG_GDP from the first cluster (1.97\% per country) and the mean percentage value from the second cluster (1.15\% per country), however, the trend is opposite, as the value is decreasing.

The hierarchy of the five countries (Belgium, Ireland, Greece, Austria, Iceland) included in cluster $3\left(\mathrm{C}_{2002}\right)$, for the year 2002 , compared to the extreme percentage values, modifies from a variable to another, such as:

- $\quad$ ENV_GDP is the most significant with 2.7\% in Austria (first place), followed by $2.4 \%$ for Ireland and Belgium (second place) and 2.3\% Greece and Iceland (third place), the mean percentage value being $2.42 \%$ per country;

- $\quad$ ENG_GDP has a mean percentage value ranging in a 95\% confidence interval with parameters LB and UP of $0.98 \%$ and $1.7 \%$ per country; Austria remains on the first place with $1.7 \%$, followed on the second place by Belgium and Greece with $1.4 \%$ and on the third place by Ireland with $1.3 \%$, Iceland being on the last place with $0.9 \%$;

- $\quad$ TRS_GDP has a mean percentage value of $0.98 \%$ per country placed between the minimum percentage value of $0.8 \%$ for Belgium, followed by Greece and Austria with $0.9 \%$, then by Ireland with $1.1 \%$ and the maximum percentage value of $1.2 \%$ belonging to Iceland; The $95 \%$ confidence interval for mean for this analysed variable is between $0.78 \%$ and $1.18 \%$. 
- $\quad$ POL_GDP does not exist for Ireland, Greece and Austria; if Belgium and Iceland have a percentage value of $0.2 \%$, the mean percentage value for these five countries that are included in the third cluster is $0.08 \%$ per country.

For cluster $4\left(\mathrm{C}_{2002}\right)$ and cluster $5\left(\mathrm{C}_{2002}\right)$, composed of eight countries, for the mean percentages of all four analysed variables, the null hypothesis is rejected and the alternative hypothesis is accepted, according to which the means of the variables ENV_GDP, ENG_GDP, TRS_GDP, POL_GDP are significant in terms of the belonging to the cluster.

The mean percentage values of the analysed variables, established for cluster 4 composed of the Czech Republic, Germany, Italy, Lithuania, Luxembourg, Hungary, Sweden, United Kingdom and for cluster 5 that includes Bulgaria, Estonia, Spain, France, Latvia, Poland, Romania, Slovakia are comparable, having quite similar percentage values.

The highest mean percentage values belong to cluster 4 compared to cluster 5, regarding the first three variables included in the analysis (ENV_GDP, ENG_GDP, TRS_GDP). The most significant difference of 0.54 percentage points is established for ENV_GDP. The mean percentages for ENV_GDP belong to a $95 \%$ confidence interval for mean established between $2.57 \%$ and $2.88 \%$ per country for cluster 4 , respectively between $2.07 \%$ and $2.30 \%$ per country for cluster 5 . The extreme percentage values can be observed at cluster 4 for the Czech Republic (2.40\%) and Sweden (2.90\%) and at cluster 5 for Estonia (2.00\%) and Poland (2.40\%).

A high level of the energy taxation, as a component of the general tax policy, is noted in the cluster of countries where the energy consumption is quite high and the state uses taxation as a Pigouvian instrument. Taking into consideration that the energy taxation tends to be higher in countries that promote green technologies and investments, the fiscal weight ratio on energy consumption affects the economic competitiveness and forces the investors to move their production capacities in countries with a more competitive cost structure.

Regarding the analysis of the evolution of variable ENG_GDP from the two clusters, the mean percentages belong to a $95 \%$ confidence interval for mean for cluster 4 ranging between $2.08 \%$ and $2.40 \%$ per country, respectively for cluster 5 ranging between $1.64 \%$ and $1.96 \%$ per country. The results and context emphasize establishing of a mean percentage value lower with 0.44 percentage points for cluster 5 compared to cluster 4 . The percentages established for variable ENG_GDP range between the minimum of $2.00 \%$ (Lithuania) and maximum of $2.60 \%$ (Luxembourg) for cluster 4 and between $1.50 \%$ (Estonia) and 2.10\% (Bulgaria) for cluster 5.

The variable TRS_GDP records a mean percentage of $0.40 \%$ per country for cluster 4 which is slightly higher than that of cluster 5 (with only 0.16 percentage points). Minor differences are also emphasized between the extreme maximum established limits: minimum of $0.10 \%$ for Luxembourg which corresponds to both clusters and maximum of $0.70 \%$ for Lithuania (cluster 4 ) and $0.40 \%$ for Latvia (cluster 5). For cluster 4, the mean percentage value ranges between $0.23 \%$ and $0.57 \%$ per country and for cluster 5 between $0.15 \%$ and $0.33 \%$ per country, at $95 \%$ confidence.

For the variable POL_GDP, the mean percentage value for cluster 4 is lower with 0.09 percentage points compared to the mean percentage value for cluster 5 . The $95 \%$ confidence interval for cluster 4 is between $0.00 \%$ and $0.12 \%$ and for cluster 5 is between $0.06 \%$ and $0.24 \%$.

Like the first cluster, cluster $6\left(\mathrm{C}_{2002}\right)$ included only three states in 2002: Croatia, Netherlands and Slovenia. Compared to the first cluster, in this cluster a similar trend of the countries regarding the four variables included in the analysis was established.

The context emphasizes the highest mean percentage value for variable ENV_GDP (of 3.63\% per country) compared to the other three variables (ENG_GDP, TRS_GDP, POL_GDP), as in the first cluster. This mean percentage value is included in a 95\% confidence interval for mean of $2.60 \%$ per country and $4.67 \%$ per country. At the same time, there is a hierarchy of the countries related to the percentage values of the variable ENV_GDP in 2002, as follows: Croatia with $4.1 \%$, Netherlands with $3.5 \%$ and Slovenia with $3.3 \%$. 
Regarding the variable ENG_GDP, it can be observed that Netherlands and Slovenia interchange their places. The oscillation of this variable leads to Slovenia occupying the second place with $2.6 \%$ and the Netherlands occupying the third place, with $1.80 \%$. In 2002, for cluster 6 , in a $95 \%$ confidence interval for mean of $1.14 \%$ per country and $3.59 \%$ per country, the mean percentage value for ENG_GDP is $2.37 \%$ per country.

In the year 2002, The Netherlands has the highest percentage value for variable TRS_GDP (1.20\%), followed by Croatia with $0.80 \%$ and Slovenia with the lowest percentage value of $0.40 \%$. The mean percentage value of TRS_GDP is 0.80 per country for cluster 6 , in the analysed year.

Regarding the variable POL_GDP, the maximum of $0.60 \%$ corresponds to Croatia and the minimum of $0.30 \%$ to Slovenia. For cluster 6 , the mean percentage in 2002 , for this variable, is $0.47 \%$ per country, in a $95 \%$ confidence interval for mean of $0.09 \%$ per country and $0.85 \%$ per country.

Cluster $7\left(\mathrm{C7}_{2002}\right)$ is represented by only one country: Denmark. The characterization variables of the energy evolution for Denmark are as follows: 4.80\% ENV_GDP, 2.6\% ENG_GDP, 1.90\% TRS_GDP and $0.30 \%$ POL_GDP.

The period 2002-2012 was marked by a series of economic and social events that trigger an environmental tax reform. This reform was manifested on two levels:

- $\quad$ the unilateral plan that mainly generated negative effects [34];

- $\quad$ the collaboration plan between states.

In 2014, revenues from environmental taxation were 343.6 billion euros, which is $2.5 \%$ of GDP and about $6.3 \%$ of the total taxes and social contributions.

In the period 2002-2014 environmental tax revenues in the EU increased by approximately $2.2 \%$ per year, while GDP grew at an annual average of 2.5\%. Compared to 2002, average income in 2014 increased by approximately 79 billion. The effect of the crisis from 2008 caused a reduction in economic activity in the EU, which led to a decrease in tax income in 2008 and 2009. From 2010, there was ascending trend for environmental tax revenues [28].

On the background of developments established during the period 2002 and 2012, the grouping and analysis process of the states, in the year 2012, based on the four environmental taxes indicators (ENV_GDP, ENG_GDP, TRS_GDP and POL_GDP) has continued.

The dendrogram that synthesizes the grouping for 2012 of the 28 EU Member States, as well as Norway and Iceland, is presented in Figure 4.

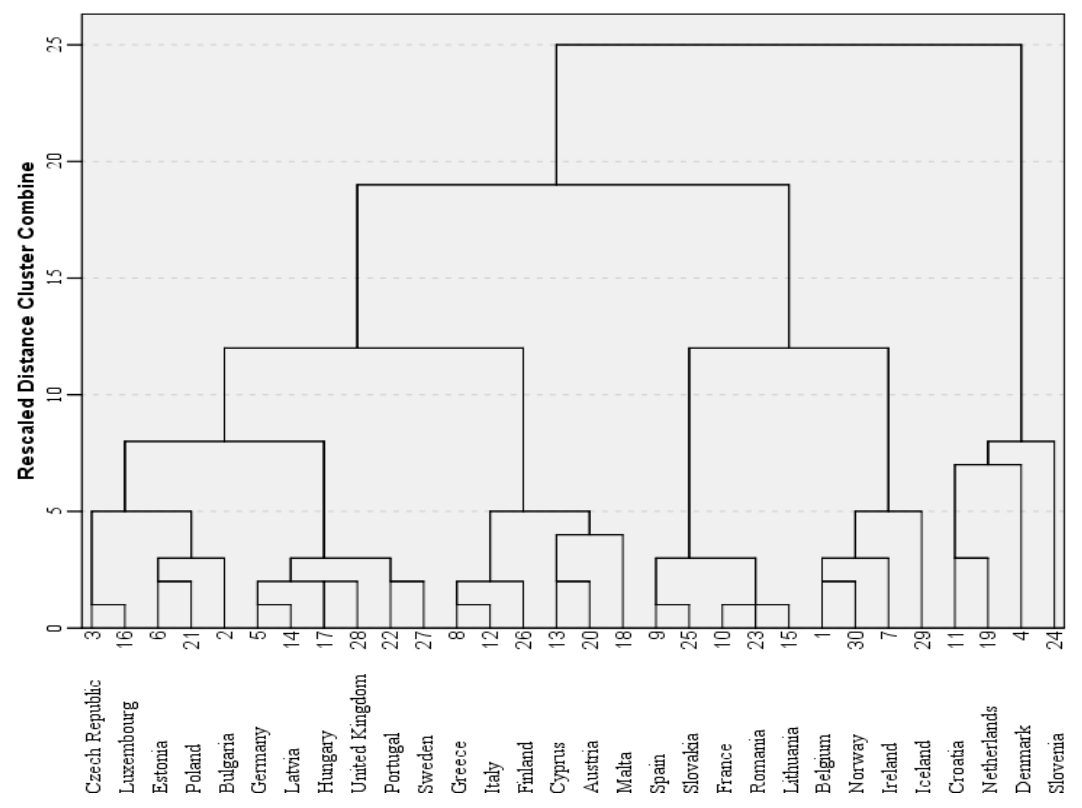

Figure 4. Dendrogram using the Ward linkage method. 
It has a relatively similar structure to the one corresponding to 2002, suggesting solutions with a number of 3 to 10 or 12 clusters. However, there are certain particularities that set them apart.

Analysing the evolution of Total Sum of Squared Error based on the number of clusters (Figure 5), potential optimal solutions regarding the number of clusters would be 6,7 or 8 . However, taking into account that the Levene Statistic values for Test for Homogeneity of Variance (Table 6) are higher for variables ENG_GDP and POL_GDP from solutions with eight and seven clusters, respectively, than the corresponding critical values $\left(\mathrm{F}_{0.05,5,22}=2.66\right.$, for eight clusters and $\mathrm{F}_{0.05,5,23}=2.64$ respectively, for seven clusters), the null hypothesis is rejected $\left(\mathrm{H}_{0_{-} 3}\right)$ and the alternative hypothesis is accepted $\left(\mathrm{H}_{0 \_}\right)$: the corresponding variances of the data series are significantly different. In these circumstances, the ANOVA methodology cannot be used to test the statistical significance of these two variables belonging to the two solutions' clusters.

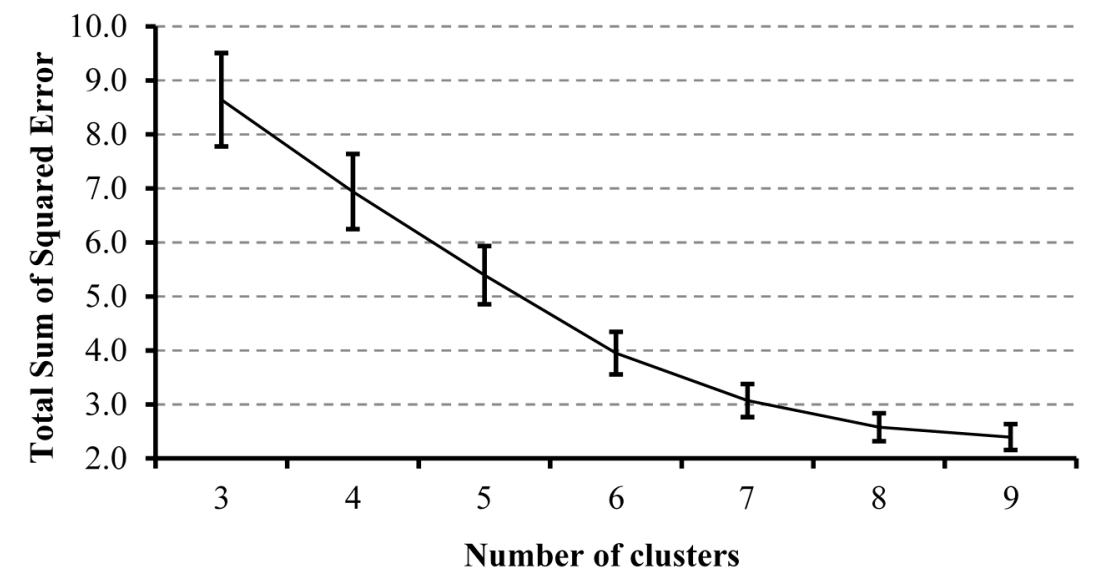

Figure 5. Number of clusters.

Table 6. Test for Homogeneity of Variances for ENG_GDP and POL_GDP.

\begin{tabular}{|c|c|c|c|c|c|c|c|c|c|}
\hline \multirow[b]{2}{*}{ Solution } & \multicolumn{3}{|c|}{8 Clusters } & \multicolumn{3}{|c|}{7 Clusters } & \multicolumn{3}{|c|}{6 Clusters } \\
\hline & $\begin{array}{l}\text { Levene } \\
\text { Statistic }\end{array}$ & $F_{0.05,5,22}{ }^{1}$ & Sign. & $\begin{array}{l}\text { Levene } \\
\text { Statistic }\end{array}$ & $F_{0.05,5,23}{ }^{2}$ & Sign. & $\begin{array}{l}\text { Levene } \\
\text { Statistic }\end{array}$ & $\mathrm{F}_{0.05,4,24}{ }^{2}$ & Sign. \\
\hline ENG_GDP & 3.218 & 2.66 & 0.025 & 2.925 & 2.64 & 0.035 & 2.365 & 2.78 & 0.081 \\
\hline POL_GDP & 2.982 & 2.66 & 0.033 & 4.348 & 2.64 & 0.006 & 3.243 & 2.78 & 0.029 \\
\hline
\end{tabular}

${ }^{1}$ The solution includes two clusters with only one element (Slovenia and Denmark, respectively); $\mathrm{d} 1=(\mathrm{k}-2)-1$;

2 the solution includes one cluster with only one element (Slovenia) $\mathrm{d} 1=(\mathrm{k}-1)-1$; Source: the authors' calculations using SPSS.

Taking into account the fact that for the solution of grouping into six clusters, the results of applying the Test for Homogeneity of Variance leads to rejecting the null hypothesis only for variable POL_GDP from the three variables, this solution was chosen.

From the six clusters (Table 7), cluster $\mathrm{C} 1$ includes 11 states, cluster $\mathrm{C} 2$ is composed of six states, cluster $\mathrm{C} 3$ contains five states, cluster 4 has four states, cluster $\mathrm{C} 5$ includes three states and C6 has only one state (Slovenia).

In order to check the significance of the belonging of the variable POL_GDP to the clusters and due to the fact that the ANOVA methodology cannot be applied, Welch's Test was used. In this case, the $\mathrm{F}$ statistics is $\mathrm{F}=3.653<\mathrm{F}_{0.05,4,7.31}$, respectively $p$-value $=0.058>\alpha=0.05$ and, thus, the null hypothesis is accepted $\left(\mathrm{H}_{0 \_}\right)$: the mean values of variable POL_GDP in the six clusters does not significantly differ. Therefore, the variable POL_GDP is not statistically significant in the achieved analysis, as it does not contribute significantly to the dissimilarity of clusters. 
Table 7. Test of Homogeneity of Variances for ENG_GDP and POL_GDP.

\begin{tabular}{ll}
\hline Cluster & \multicolumn{1}{c}{ Countries Included in Clusters } \\
\hline $\mathrm{C}_{2} 2012$ & $\begin{array}{l}\text { Bulgaria, Czech Republic, Germany, Estonia, Latvia, Luxembourg, Hungary, Poland, Portugal, } \\
\text { Sweden, United Kingdom }\end{array}$ \\
$\mathrm{C} 2_{2012}$ & Greece, Italy, Cyprus, Malta, Austria, Finland \\
$\mathrm{C}_{2012}$ & Spain, France, Lithuania, Romania, Slovakia \\
$\mathrm{C}_{2012}$ & Belgium, Ireland, Iceland, Norway \\
$\mathrm{C}_{2012}$ & Denmark, Croatia, Netherlands \\
$\mathrm{C}_{2012}$ & Slovenia \\
\hline
\end{tabular}

Source: the authors' own construction.

For the other three considered variables, taking into the account that they satisfy the Test for Homogeneity of Variance (the data series variances corresponding to them do not significantly differ), the ANOVA methodology was used to analyse the significance of their belonging to the chosen solution's clusters (Table 8).

Table 8. ANOVA results for the solution with six clusters.

\begin{tabular}{cccc}
\hline Variable & $\mathbf{F}_{\mathbf{0 . 0 5 , 5 , 2 4}}$ & $\mathbf{F}$ & Significance (Sign.) \\
\hline ENV_GDP & 2.62 & 36.613 & 0.000 \\
ENG_GDP & 2.62 & 13.875 & 0.000 \\
TRS_GDP & 2.62 & 11.915 & 0.000 \\
\hline
\end{tabular}

Source: the authors' calculations using SPSS.

Because the values of $F$ statistics are significantly higher than the critical value $F_{0.05,5,24}=2.62$, the null hypothesis is rejected $\left(\mathrm{H}_{0 \_}\right)$and, thus, their values are significant in terms of their belonging to the clusters. The values of the means for analysed variables and their $95 \%$ Confidence Interval for Mean are presented in Table 9.

Table 9. The values of clusters centre (Means) for the variables ENV_GDP, ENG_GDP, TRS_GDP and POL_GDF in the year 2012 and their 95\% Confidence Interval for Mean.

\begin{tabular}{|c|c|c|c|c|c|c|c|c|c|c|c|c|c|}
\hline \multirow{2}{*}{ Cluster } & \multirow{2}{*}{$\mathbf{N}$} & \multicolumn{3}{|c|}{ ENV_GDP } & \multicolumn{3}{|c|}{ ENG_GDP } & \multicolumn{3}{|c|}{ TRS_GDP } & \multicolumn{3}{|c|}{ POL_GDP * } \\
\hline & & Mean & SD & SE & Mean & SD & SE & Mean & SD & SE & Mean & SD & SE \\
\hline $\mathrm{C} 1$ & 11 & 2.48 & 0.20 & 0.06 & 2.07 & 0.26 & 0.08 & 0.32 & 0.17 & 0.05 & 0.10 & 0.10 & 0.03 \\
\hline $\mathrm{C} 2$ & 6 & 2.85 & 0.26 & 0.11 & 1.95 & 0.30 & 0.12 & 0.85 & 0.24 & 0.10 & 0.03 & 0.05 & 0.02 \\
\hline $\mathrm{C} 3$ & 5 & 1.76 & 0.11 & 0.05 & 1.52 & 0.15 & 0.07 & 0.18 & 0.11 & 0.05 & 0.06 & 0.05 & 0.02 \\
\hline $\mathrm{C} 4$ & 4 & 2.30 & 0.18 & 0.09 & 1.28 & 0.13 & 0.06 & 0.75 & 0.34 & 0.17 & 0.20 & 0.12 & 0.06 \\
\hline C5 & 3 & 3.57 & 0.35 & 0.20 & 1.93 & 0.25 & 0.15 & 1.10 & 0.30 & 0.17 & 0.43 & 0.21 & 0.12 \\
\hline C6 & 1 & 3.80 & & & 3.10 & & & 0.40 & & & 0.30 & & \\
\hline
\end{tabular}

* Although variable POL_GDP does not significantly contribute to the dissimilarity of the six clusters, it was taken into account for a better comparability with the structure and characteristics of the clusters for year 2002; Source: the authors' calculations using SPSS; Note: SD-Std. Deviation; SE-Std. Error.

The same detailed analysis type of the results from Table 9 was achieved for all the countries included in the clusters, by studying and comparing the evolution levels of the four variables (ENV_GDP, ENG_GDP, TRS_GDP, POL_GDP), for the year 2012.

A clearer emphasizing of evolution of variables ENV_GDP, ENG_GDP, TRS_GDP and POL_GDP on clusters has taken into account their mean values and has provided a suggestive graphical representation (Figure 6). 


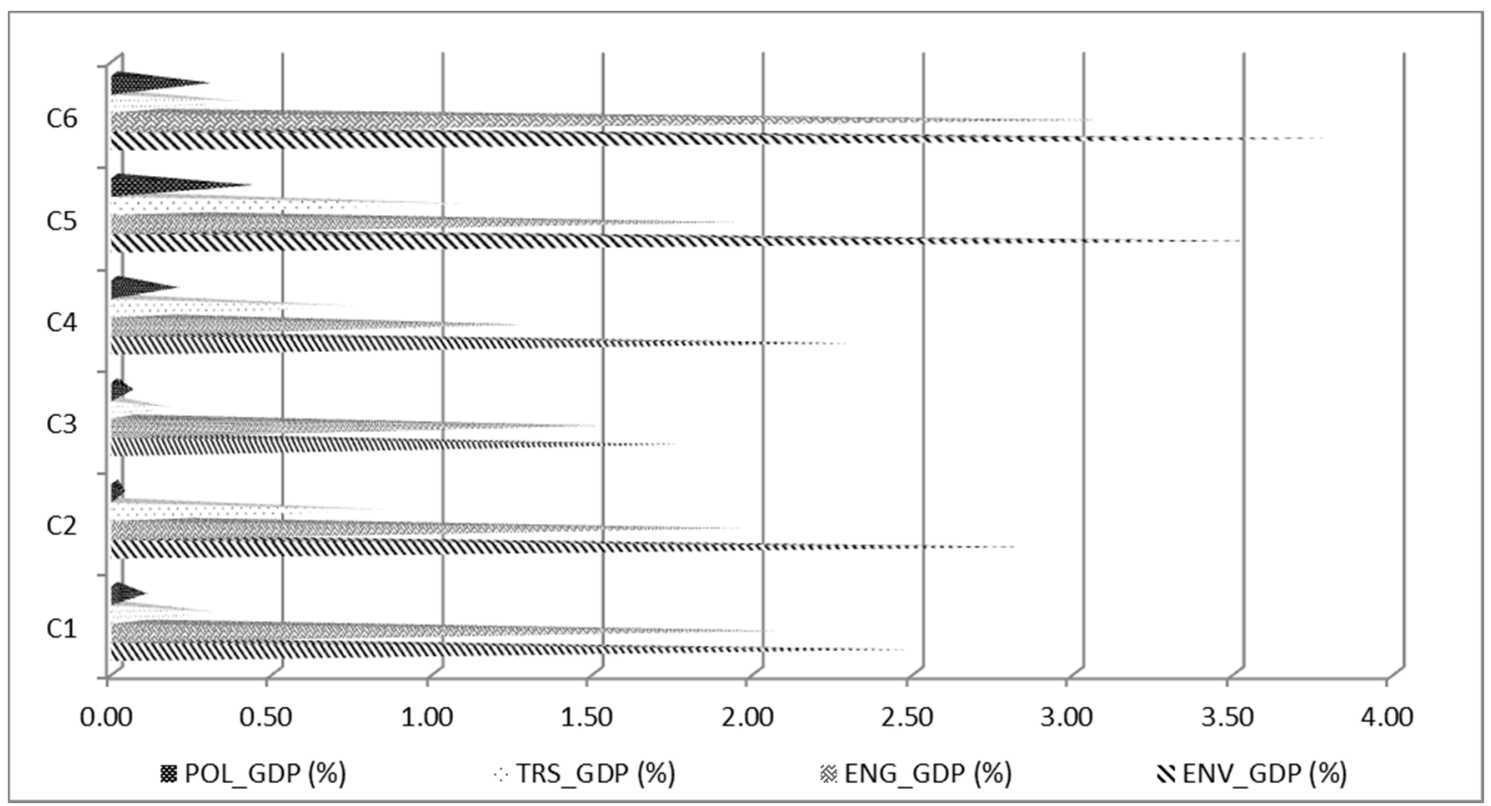

Figure 6. Evolution of ENV_GDP, ENG_GDP, TRS_GDP, POL_GDP in the 2012 clusters.

The economic crisis has brought to the fore the effects of the energy taxation on modelling the domestic economic structures. The energy taxation is to be considered, in this case, both one of the political and economic instruments and, in the same time, a market instrument used for promoting sustainable development. Thus, in 2012, cluster $1\left(\mathrm{Cl}_{2012}\right)$ includes the most countries compared to the other clusters: Bulgaria, the Czech Republic, Germany, Estonia, Latvia, Luxembourg, Hungary, Poland, Portugal, Sweden, United Kingdom. For the countries from $\mathrm{Cl}_{2012}$, the mean percentage value is established in relation to the variables, as follows:

- $\quad$ in the case of ENV_GDP, between a minimum percentage of $2.20 \%$ (Germany and Portugal) and a maximum percentage of $2.80 \%$ (Bulgaria), the mean percentage value is $2.48 \%$, in a $95 \%$ confidence interval for mean of $2.35 \%$ per country and $2.62 \%$ per country;

- for ENG_GDP the mean percentage value is $2.07 \%$ per country, belonging to a $95 \%$ confidence interval for mean of $1.90 \%$ per country and $2.52 \%$ per country; as in the case of the previous analysed variable, the same countries (except Germany) form the extreme limits, but with different percentage values: minimum of $1.70 \%$ and maximum of $2.50 \%$;

- for TRS_GDP, in a 95\% confidence interval for mean of $0.20 \%$ per country and $0.43 \%$ per country, the mean percentage value of $0.32 \%$ per country is established between the minimum percentage value of $0.10 \%$ for Estonia, respectively Luxembourg and the maximum percentage value of $0.60 \%$ for the United Kingdom;

- at $0.10 \%$ per country, in a $95 \%$ confidence interval for mean of $0.03 \%$ per country and $0.17 \%$ per country, for variable POL_GDP. The limits of interval in setting the mean for this variable are: $0.00 \%$ (Czech Republic, Luxembourg, Portugal, Sweden) and 0.30\% (Estonia).

The implicit energy taxation policy could correct the market dysfunctionalities and improve economic efficiency by using the market instruments in order to approach the negative economic externalities due to the energy resources usage. As shown in Figure 6, the energy taxation policy instruments are not used homogeneously and coherently among the states in the clusters. Some of the EU-28 Member States have used energy taxation as an instrument for promoting low-carbon economy, as well as for promoting innovative and less polluting industries and, not the least, for increasing the domestic competitiveness through ensuring a high level of employment. 
The main characteristic of cluster $2\left(\mathrm{C}_{2012}\right)$ is that it includes six countries (Greece, Italy, Cyprus, Malta, Austria, Finland) with a significant mean percentage value for variable ENV_GDP of 2.85\% per country, taking into account the large number of countries included in the cluster, compared to $\mathrm{C}_{2012}$, $\mathrm{C}_{2012}, \mathrm{C}_{2012}$ and $\mathrm{C}_{2012}$. The mean percentage value placed between the minimum of $2.40 \%$ from Austria and the maximum of $3.10 \%$ from Finland is assigned to a $95 \%$ confidence interval for mean of $2.58 \%$ per country and $3.12 \%$ per country.

In $\mathrm{C}_{2012}$, it is established, for Austria and Malta, the lowest percentage value of $1.60 \%$ for variable ENG_GDP, while the maximum of $2.30 \%$ corresponds to Italy. Besides these extreme percentage values, the others of $1.90 \%$ (Cyprus), $2.10 \%$ (Finland) and $2.20 \%$ (Greece) contribute to the mean percentage value of $1.95 \%$ per country and a $95 \%$ confidence interval for mean of $1.63 \%$ per country and $2.27 \%$ per country. Thus, a reform of the energy taxation policy may encourage a modification of the tax burden from wage income to resource usage and creation of a sustainable economic growth pattern.

The variable TRS_GDP in $\mathrm{C}_{2012}$ is characterized by an interval for mean, of $0.60 \%$ per country and $1.10 \%$ per country, at $95 \%$ confidence for a mean percentage value of $0.85 \%$, while for ENG_GDP, Italy represents the upper limit by the recorded percentage value, for TRS_GDP this country represents, through its value of $0.60 \%$, the lower limit in determining the mean percentage value. Between the minimum limit represented by Italy and the maximum limit in Malta (1.30\%), there are the following countries: Greece $0.70 \%$, Cyprus and Austria 0.80\%, respectively Finland 0.90\%.

In $\mathrm{C}_{2012}$, the mean percentage value of $0.03 \%$ for POL_GDP is the result established between two countries with insignificant share $(0.10 \%)$ of the pollution in GDP (Malta, Finland) and other four countries that do not have such contributions in GDP (Greece, Italy, Cyprus, Austria).

As the results shows, the energy taxation is considered, in this situation, a factor that prevents economic development rather than promotes it. The energy taxation policy, used as a market instrument, should contribute in a higher manner to the transition process to a more eco-efficient and eco-friendly economy. The share of the indicators proves that for the most EU-28 Member States, energy taxation was used more to mitigate the effects of the economic crisis than to develop and promote green investments, as well as to design a new economic paradigm by changing the energy consumption patterns.

For the year 2012, the hierarchy of the countries (Spain, France, Lithuania, Romania, Slovakia) included in cluster $3\left(\mathrm{C}_{2012}\right)$, on each studied variable, is analysed taking into account the extreme percentage values but also the confidence intervals.

ENV_GDP has a mean percentage value of $1.76 \%$ per country, established in a $95 \%$ confidence interval for mean of $1.62 \%$ and $1.90 \%$ per country. Romania is on the first place from the countries in $\mathrm{C}_{2012}$ with $1.90 \%$, followed on the second place by France and Slovakia with $1.80 \%$ and on the third place by Lithuania with $1.70 \%$, while on the last place is Spain with $1.60 \%$.

Spain and Romania maintain their places in the ranking of variable ENG_GDP for cluster $\mathrm{C}_{2012}$. Between the two countries, with a minimum percentage value of $1.30 \%$ and a maximum percentage value of $1.70 \%$, are the following countries: Lithuania with $1.60 \%$, France and Slovakia with $1.50 \%$. In this context, the mean percentage value of the variable ENG_GDP for $\mathrm{C}_{2012}$ is $1.52 \%$ per country with a $95 \%$ confidence interval for mean of $1.34 \%$ per country and $1.70 \%$ per country.

Regarding the variable TRS_GDP, there is a mean percentage value of $0.18 \%$ per country, ranging between the minimum percentage value of $0.0 \%$ for Lithuania, followed by France, Romania and Slovakia with $0.20 \%$ and the maximum percentage value of $0.30 \%$ for Spain. For cluster $\mathrm{C}_{2012}$ and variable TRS_GDP there is a 95\% confidence interval for mean between $0.04 \%$ and $0.32 \%$.

The variable POL_GDP is inexistent for Spain and Slovakia. For the other three countries (France, Lithuania, Romania), POL_GDP is $0.10 \%$ and, at the general level, for the five countries that compose cluster $\mathrm{C}_{2012}$, there is a mean percentage value of $0.06 \%$ per country. So, as it is shown by the results and it is argued in the literature [35], the implicit tax rates on energy are only significantly inversely related to the efficiency measure. 
The analysis of cluster 4 in $2012\left(\mathrm{C}_{2012}\right)$ regards only four countries: Belgium, Ireland, Iceland and Norway, for which the evolution levels of the four variables: ENV_GDP, ENG_GDP, TRS_GDP, POL_GDP are studied and compared.

The research starts with variable ENV_GDP. The mean percentage value of this variable, compared to the other three variables (ENG_GDP, TRS_GDP, POL_GDP), is the highest, namely $2.30 \%$ per country. This mean percentage value is included in a 95\% confidence interval for mean of $2.01 \%$ per country and $2.59 \%$ per country. Iceland with $2.50 \%$, Norway with $2.40 \%$, Belgium with $2.20 \%$ and Ireland with $2.10 \%$ represent the hierarchy of the countries, based on the percentage values of variable ENV_GDP, in 2012, for $\mathrm{C}_{2012}$.

For variable ENG_GDP, the hierarchy pyramid of the countries is reversed. The maximum percentage value belongs to Iceland with $1.40 \%$, followed by Belgium and Ireland with $1.30 \%$ and the minimum percentage of $1.10 \%$ belongs to Norway for $\mathrm{C}_{2012}$. In the year 2012 , for cluster 4 , the mean percentage of ENG_GDP is $1.28 \%$, for a $95 \%$ confidence interval for mean of $1.07 \%$ per country and $1.48 \%$ per country.

In $\mathrm{C}_{2012}$, Norway is on the first place for variable TRS_GDP with $1.10 \%$ and Iceland is on the last place with $0.30 \%$. In between, there are Ireland with $0.90 \%$ and Belgium with $0.70 \%$. These percentage values led to a mean percentage of TRS_GDP for cluster $\mathrm{C}_{2012}$ of $0.75 \%$ per country in a $95 \%$ confidence interval for mean of $0.21 \%$ per country and $1.29 \%$ per country. As it can be remarked, despite the fact that the EU-28 Member States have chosen, for a long period of time, during 2002-2008, to decrease the energy taxation in order to promote extensive economic growth, after the economic crisis the energy taxation has become an efficient tool for mobilizing financial revenues to the national budgets.

Considering variable POL_GDP, the maximum of $0.30 \%$ belongs to Ireland and Iceland and the minimum of $0.10 \%$ belongs to Belgium and Norway. For $\mathrm{C}_{2012}$, the mean percentage is $0.20 \%$ per country for this variable in a $95 \%$ confidence interval for mean of $0.02 \%$ per country and $0.38 \%$ per country.

In 2012, cluster $5\left(\mathrm{C}_{2012}\right)$ is composed of three countries: Denmark, Croatia and Netherlands. Compared to the other three variables included in the analysis (ENG_GDP, TRS_GDP, POL_GDP), in 2012 , the mean percentage value of $3.57 \%$ per country of ENV_GDP for $C_{2012}$ is the highest. This established mean percentage value is included between a minimum of $3.20 \%$ for Croatia and a maximum of $3.90 \%$ for Denmark, while Netherlands has $3.60 \%$. This evolution of variable in $\mathrm{C}_{2012}$ has led to a $95 \%$ confidence interval for mean of $2.69 \%$ per country and $4.44 \%$ per country.

The analysis of the next two variables (ENG_GDP, TRS_GDP) includes a hierarchy of the three countries identical to the one corresponding to variable ENV_GDP for $\mathrm{C}_{2012}$. In this cluster, Croatia is the country with the lowest percentage values of $1.70 \%$ for ENG_GDP and $0.80 \%$ for TRS_GDP, and Denmark has maximum values of $2.20 \%$ and $1.40 \%$ for the two analysed variables. Based on the percentages of variables ENG_GDP and TRS_GDP for Netherlands, the mean percentages for $\mathrm{C}_{2012}$, in 2012, were established as 1.93\% per country for ENG_GDP and 1.10\% per country for TRS_GDP.

The variable POL_GDP reverses the places in hierarchy between Croatia and Denmark. For 2012, in the cluster $\mathrm{C}_{2012}$, the minimum percentage is $0.20 \%$ for Denmark and the maximum of $0.60 \%$ for Croatia. The mean percentage of POL_GDP, for cluster 5, is 0.43\% per country, in 2012.

Regarding cluster $6\left(\mathrm{C}_{2012}\right)$, the main characteristic is that it consists of only one country: Slovenia. For Slovenia, the variables that characterize the energy evolution are: 3.80\% ENV_GDP, 3.1\% ENG_GDP, $0.40 \%$ TRS_GDP and $0.30 \%$ POL_GDP.

In conclusion, significant changes regarding the values of those four taxes took place as a result of the economic and social transformations that were recorded between 2002 and 2012, in those 30 states. These changes have led to the migrations of the states included in clusters $\mathrm{C}_{2002}, \mathrm{C}_{2002}$, $\mathrm{C}_{2002}, \mathrm{C}_{2002}$ and $\mathrm{C}_{2002}$, especially, to clusters $\mathrm{C}_{2012}$ and $\mathrm{C}_{2012}$. Thus, if in 2002 , the clusters $\mathrm{C1}_{2002}$, $\mathrm{C} 2_{2002}$ and $\mathrm{C}_{2002}$ included only 10 states (33.34\%), in 2012 their number has increased to $22(73.34 \%)$. The common features of those 22 states that in 2012 were included in clusters $\mathrm{Cl}_{2012}, \mathrm{C}_{2012}$ and $\mathrm{C}_{2012}$ 
are represented by the decreasing of total environmental taxes as \% to GDP (from 3.13\%, 3.15\% and $2.42 \%$, in 2002 , to $2.48 \%, 2.85 \%$ and, respectively, $1.76 \%$ in 2012 ), decreasing of transport taxes as \% to GDP (from $1.13 \%, 1.85 \%$ and $0.98 \%$, in 2002 , to $0.32 \%, 0.85 \%$ and, respectively $0.18 \%$, in 2012 ), as well as by slight increases of energy taxes as \% to GDP (from 1.97\%, $1.15 \%$ and $1.34 \%$, in 2002, to $2.07 \%$, $1.95 \%$ and, respectively $1.52 \%$, in 2012). Regarding the pollution taxes as \% to GDP, the mean values of this indicator for the states from clusters $\mathrm{C}_{2012}$ and $\mathrm{C}_{2012}$ have maintained approximately constant. The exception is represented by the states from cluster $\mathrm{Cl}_{2012}$ where the mean value of this indicator has increased from $0.03 \%$ in 2002 , to $0.10 \%$ in 2012.

In Croatia, Denmark, Netherlands and Slovenia a relatively different situation is recorded, where, although the shares of those four taxes in GDP in 2012 are lower than the ones recorded in 2002, their values continue to be quite high. This fact maintains these states on different positions in comparison with the other analysed states.

The environmental taxation, including energy, has different levels among the EU-28 Member States and shows the interest of the state in promoting environment friendly technologies and reducing the dependence on energy imports [36]. If it is taken into consideration the contribution of the environmental taxation, including energy, on creating GDP, as it is shown in literature [22], "the ratio of environmental tax revenues to GDP differs between Member States, with Denmark (4.1\%), Slovenia and Croatia (both 3.9\%) having the highest ratios and Lithuania (1.7\%), Slovakia and Spain (both 1.8\%) registering the lowest" [22].

\section{Conclusions}

In Europe, environmental taxation, including energy taxation, has led to a genuine environmental tax reform, during the analysed period of 2002-2012. Changes in the grouping of the states in 2012 compared to 2002, in different environmental tax categories, reflect, to some extent, the behaviour of economic operators.

In 2012, compared to 2002, ENV_GDP records significant fluctuations in time, from one cluster to another and, implicitly, from one country to another. The fluctuations are emphasized through the increase of mean percentage values established in 2012 compared to 2002 for clusters $5\left(\mathrm{C}_{2012}\right)$ and 6 $\left(\mathrm{C}_{2012}\right)$ and the decrease for the other four clusters $\left(\mathrm{Cl}_{2012}, \mathrm{C}_{2012}, \mathrm{C}_{2012}, \mathrm{C}_{2012}\right)$. At the same time, the overall analysis of variable ENV_GDP, in 2012 compared to 2002, has synthesized two evolution directions: mean percentage increase and decrease.

The evolution, in the sense of mean percentage increase for ENV_GDP in 2012 compared to 2002, was established for a small part of the countries included in the analysis. Thus, $\mathrm{Cl}_{2012}$ recorded an increase with 2.19 percentage points per country of ENV_GDP through Bulgaria, Estonia, Latvia, Poland which transfer from $\mathrm{C}_{2002}$, while $\mathrm{C}_{2012}$ with 0.66 percentage points per country through Greece and Austria from $\mathrm{C}_{2002}$, respectively with 0.12 percentage points per country through Italy from $\mathrm{C4}_{2002}$. Although Slovenia does not change its cluster that is cluster 6, it shows a change in the sense of a mean percentage increase with 0.17 percentage points per country in $\mathrm{C6}_{2012}$ compared to $\mathrm{C}_{2002}$.

The mean percentage decreases for ENV_GDP have led to a descending trend for most of the countries included in the research. Thus, it can be observed that there are significant changes of the clusters' components in 2012 compared to 2002. Portugal, element of $\mathrm{C}_{2002}$, stays loyal to this cluster in 2012, although, overall, $\mathrm{C1}_{2012}$ records a mean percentage decrease of ENV_GDP with $0.65 \%$ percentage points per country. This significant difference is also the result of the percentage values established in 2012 for Germany, Hungary, Sweden, Luxembourg, Czech Republic and United Kingdom, which moved from the cluster $\mathrm{C}_{2002}$. A similar situation is established with Cyprus and Malta, elements of clusters $\mathrm{C}_{2} 2002$ and $C 2_{2012}$, the difference between clusters being 0.30 percentage points per country.

For cluster $\mathrm{C}_{2012}$, the mean percentage value of ENV_GDP is lower with 0.28 percentage points per country compared to the one of $\mathrm{Cl}_{2002}$ from which Finland has come. The same decreasing 
process can be seen for $\mathrm{C}_{2012}$ through Lithuania from $\mathrm{C}_{2002}$ with 0.97 percentage points per country, respectively through Spain, France, Romania, Slovakia from $\mathrm{C}_{2002}$ with 0.43 percentage points per country. Cluster $\mathrm{C}_{2012}$ includes Norway from $\mathrm{Cl}_{2002}$, with a decrease of 0.83 percentage points per country and three countries from $\mathrm{C}_{2002}$ (Belgium, Ireland and Iceland) which led to a decreasing trend of the analysed variable average with 0.12 percentage points per country. The same trend is reported for Croatia and the Netherlands from $\mathrm{C6}_{2002}$, respectively Denmark from $\mathrm{C}_{2002}$, which will become elements of $\mathrm{C}_{2012}$, causing decreases of 0.06 percentage points per country, respectively 1.23 percentage points per country.

The mean percentage fluctuations of the variable ENG_GDP recorded in time, on each country and from one cluster to another, are similar to the fluctuations of the previously analysed variable (ENV_GDP). The notified exceptions are as follows:

- $\quad \mathrm{C1}_{2012}$ for which there is an increase of the mean percentage of ENG_GDP from $1.97 \%$ per country to $2.07 \%$ per country, represented, in part, by Portugal from $\mathrm{C}_{2002}$;

- $\quad C 2_{2012}$, with Cyprus and Malta which lead to an increasing process of the mean percentage value with 0.8 percentage points in 2012 compared to 2002.

The variation trends of the mean percentage values for variable TRS_GDP are similar to variable ENV_GDP. For this analysed variable, there are different observed situations as follows:

- $\quad$ C2 2012 where, for TRS_GDP, there is a mean percentage decrease from $0.98 \%$ per country from $\mathrm{C}_{2002}$ to $0.85 \%$, represented by Greece and Austria, respectively a mean percentage increase with 0.45 percentage points from $\mathrm{C}_{2002}$ represented by Italy.

- $\quad \mathrm{C}_{2012}$, for which there is a mean percentage increase, compared to 2002 with $0.30 \%$ percentage points per country for $\mathrm{C}_{2002}$ through Croatia and Netherlands.

- $\quad \mathrm{C6}_{2012}$ is represented by Slovenia with a mean percentage of $0.40 \%$ per country, lower than that of cluster 6 in 2002 that belonged to in that year.

The variable POL_GDP is nearly in the opposite direction as ENV_GDP. The increases of mean percentage values for variable POL_GDP determined an ascending trend for many countries included in the research and significant changes of the clusters' components in 2012 compared to 2002. The insignificant mean percentage increase from $\mathrm{Cl}_{2012}$ with 0.04 percentage points per country is based on Germany, Hungary, Sweden, Luxembourg, Czech Republic, United Kingdom which represented $\mathrm{C}_{2002}$. The same situation is established for Portugal in $\mathrm{C}_{2002}$ which does not modify its cluster in 2012 although, overall, there is a mean percentage increase of variable POL_GDP with 0.07 percentage points per country. Norway from $\mathrm{Cl}_{2002}$ will be transferred in cluster $\mathrm{C4}_{2012}$, the increase between clusters being 0.17 percentage points per country. Three countries from $\mathrm{C}_{2002}$ (Belgium, Ireland and Iceland) also determines an increasing trend of the analysed variable mean with 0.12 percentage points per country. Denmark, element of $\mathrm{C7}_{2002}$, will become a component of $\mathrm{C}_{2012}$, leading to an increase of the mean percentage value between clusters of 0.13 percentage points per country.

At the same time, the variable POL_GDP also recorded decreases of the mean percentage values between the clusters from 2012 compared to the clusters from 2002. For $\mathrm{Cl}_{2012}$ there is a decrease of 0.05 percentage points per country of the variable through Bulgaria, Estonia, Latvia and Poland which are transferred from $\mathrm{C}_{2002}$. A similar situation is identified for $\mathrm{C}_{2012}$, where there is a decrease of 0.05 percentage points per country through Greece and Austria from $\mathrm{C}_{2002}$, respectively with 0.03 percentage points per country through Italy from $\mathrm{C}_{2002}$. Components of cluster $\mathrm{C}_{2002}$, Cyprus and Malta, also are components for $\mathrm{C}_{2012}$, the difference between them being 0.02 percentage points per country. The same decreasing process can also be seen for $\mathrm{C}_{2012}$ through Spain, France, Romania and Slovakia from $\mathrm{C}_{2002}$ with 0.12 percentage points per country, but also for $\mathrm{C}_{2012}$ through Croatia and Netherlands from $\mathrm{C6}_{2002}$, with a difference of 0.04 percentage points per country. An identical trend is notified for Slovenia which records a change in the direction of mean percentage decrease with 0.17 percentage points per country in $\mathrm{C6}_{2012}$ compared to $\mathrm{C6}_{2002}$. This variable POL_GDP is the 
only variable that does not change its mean percentage value of $0.06 \%$ per country from cluster $\mathrm{C}_{2002}$ to cluster $\mathrm{C}_{2012}$. Taking into account these observations, we can determine that at UE-28 Member States level an uniformity process (a relative convergence) of the values of the four indicators (total environmental taxes as a percentage of GDP, energy taxes as a percentage of GDP, transport taxes as a percentage of GDP, pollution taxes as a percentage of GDP) has been carried out. Initiatives and plans undertaken by various countries regarding the environmental taxation, including energy taxation, aimed at:

- $\quad$ reducing negative effects on the environment;

- promoting good environmental behaviour;

- $\quad$ obtaining incomes for environmental protection;

Countries' efforts have been reported and visible as a response to the financial and economic crisis, from 2008. Changes occurred in the economic models of behaviour can be assigned to incomes that are reduced as a result of using higher tax rates, or using some low environmental tax rates.

In conclusion, it can be stated that in the EU-28 Member States, the environmental policy is oriented primarily towards pollution control and natural resources. In this end, they have used economic instruments such as environmental taxes, tradable permits, royalties and taxes, deposit-refund systems, as well as subsidies.

Environmental taxation, including energy taxation, has taken into account both supporting economic operator behaviour and fulfilling environmental objectives. The application of these taxes, in different fields and the impact in the countries included in the analysis represent references for emphasizing the economic models of behaviour and in the process of grouping them by various criteria.

The EU-28 energy taxation system could be considered as a global standard in terms of energy taxation and greenhouse gases reduction. Also, it is solidly built on sustainable principles and, at the same time, is effective. Thus, the revenues obtained from the implementation of fiscal regulations in the field of energy must be used and, also, targeted, in a much higher manner, to support the financing of projects and measures aimed to protect the environment, to promote and to reward manufacturers that choose to introduce new eco-efficient technologies of production, as well as to adapt to climate changes.

Taking into the consideration the results obtained in the analysis, it could be appreciated that the main objectives of this study were achieved. During the analysis, clusters were designed on the basis of the influence of energy taxation in developing an EU-28 economic paradigm and also there possible convergences and causalities between GDP growth and energy taxation among the EU-28 Member States were identified and marked. The results obtained during the research led to the conclusion that the environmental policy and, especially energy policy, could be considered instruments that can be used to design a convergence model among the EU-28 Member States.

Author Contributions: In this article, all the authors were involved in the documentation phase, in choosing the research methodology, in data analysis, as well as in results analysis and in discussions. All the authors have participated to the manuscript preparation and have approved the submitted manuscript.

Conflicts of Interest: The authors declare no conflict of interest.

\section{References}

1. Talus, K. EU Energy Law and Policy: A Critical Account; Oxford University Press: Oxford, UK, 2013.

2. Von Weizsäcker, E.U.; Jesinghaus, J. Ecological tax reform. In Ernst Ulrich von Weizsäcker. A Pioneer on Environmental, Climate and Energy Policies; von Weizsäcker, E.U., Ed.; Springer: Heidelberg, Germany, 2014.

3. Filipović, S.; Golušin, M. Environmental taxation policy in the EU-New methodology approach. J. Clean Product. 2015, 88, 308-317. [CrossRef]

4. Cavallari, L.; Romano, S. Fiscal policy in Europe: The importance of making it predictable. Econ. Model. 2017, 60, 81-97. [CrossRef]

5. Møller, N.F. Energy demand, substitution and environmental taxation: An econometric analysis of eight subsectors of the Danish economy. Energy Econ. 2017, 61, 97-109. [CrossRef] 
6. Andrei, J.; Mieila, M.; Popescu, G.H.; Nica, E.; Cristina, M. The impact and determinants of environmental taxation on economic growth communities in Romania. Energies 2016, 9, 902. [CrossRef]

7. Maltby, T. European Union energy policy integration: A case of European Commission policy entrepreneurship and increasing supranationalism. Energy Policy 2013, 55, 435-444. [CrossRef] [PubMed]

8. Helm, D. The European framework for energy and climate policies. Energy Policy 2014, 64, 29-35. [CrossRef]

9. Lofsted, R.E.; Collier, U. Cases in Climate Change Policy: Political Reality in the European Union; Routledge: London, UK, 2014.

10. Lee, J.W. The contribution of foreign direct investment to clean energy use, carbon emissions and economic growth. Energy Policy 2013, 55, 483-489. [CrossRef]

11. Golub, J. (Ed.) New Instruments for Environmental Policy in the EU; Routledge: London, UK, 2013.

12. Miller, S.J.; Vela, M.A. Are Environmentally Related Taxes Effective? Inter-American Development Bank: Washington, DC, USA, 2013.

13. Bruvoll, A.; Larsen, B.M. Greenhouse gas emissions in Norway: Do carbon taxes work? Energy Policy 2004, 32, 493-505. [CrossRef]

14. Liang, Q.M.; Fan, Y.; Wei, Y.M. Carbon taxation policy in China: How to protect energy-and trade-intensive sectors? J. Policy Model. 2007, 29, 311-333. [CrossRef]

15. Sterner, T. Fuel taxes: An important instrument for climate policy. Energy Policy 2007, 35, 3194-3202. [CrossRef]

16. Yan, X.; Crookes, R.J. Reduction potentials of energy demand and GHG emissions in China's road transport sector. Energy Policy 2009, 37, 658-668. [CrossRef]

17. Pang, X.; Mörtberg, U.; Brown, N. Energy models from a strategic environmental assessment perspective in an EU context-What is missing concerning renewables? Renew. Sustain. Energy Rev. 2014, 33, 353-362. [CrossRef]

18. Jenkins, J.D. Political economy constraints on carbon pricing policies: What are the implications for economic efficiency, environmental efficacy, and climate policy design? Energy Policy 2014, 69, 467-477. [CrossRef]

19. Ezcurra, M.V.; Jessen, P.W. Energy Taxation and Key Legal Concepts in the EU State Aid Context: Looking for a Common Understanding; CEU Ediciones: Madrid, Spain, 2015.

20. Kanellakis, M.; Martinopoulos, G.; Zachariadis, T. European energy policy-A review. Energy Policy 2013, 62, 1020-1030. [CrossRef]

21. Anger, N.; Böhringer, C.; Lange, A. The political economy of energy tax differentiation across industries: Theory and empirical evidence. J. Regul. Econ. 2015, 47, 78-98. [CrossRef]

22. European Union. Taxation Trends in the European Union, Directorate-General for Taxation and Customs Union (DG TAXUD); Luxembourg Publications Office of the European Union: Luxembourg, 2016.

23. Krozer, Y. Cost and benefit of renewable energy in the European Union. Renew. Energy 2013, 50, 68-73. [CrossRef]

24. Dowling, P. The impact of climate change on the European energy system. Energy Policy 2013, 60, 406-417. [CrossRef]

25. Gevorkyan, A.V. Innovative Fiscal Policy and Economic Development in Transition Economies; Routledge: London, UK, 2013.

26. Rausch, S. Fiscal consolidation and climate policy: An overlapping generations perspective. Energy Econom. 2013, 40, S134-S148. [CrossRef]

27. Gorunescu, F. Data Mining. Concepte, Modele şi Tehnici; Editura Albastră: Cluj Napoca, Romania, 2006.

28. Eurostat Statistics Explained. Environmental Tax Statistics. 2016. Available online: http://ec.europa.eu/ eurostat/statistics-explained/index.php/Environmental_tax_statistics (accessed on 15 July 2016).

29. Rotaru, T.; Badescu, G.; Culic, I.; Mezei, E.; Mureșan, C. Metode Statistice Aplicate în Științele Sociale; Rotaru, T., Ed.; Editura Polirom: Iași, Romania, 2006.

30. Marinoiu, C. Bootstrap stability evaluation and validation of clusters based on agricultural indicators of EU countries. Econ. Insights Trends Chall. 2016, 5, 65-72.

31. Peeples, M.A. R Script for K-Means Cluster Analysis. Available online: http://www.mattpeeples.net/ kmeans.html (accessed on 13 July 2016).

32. Zaiontz, C. Real Statistics Using Excel. Available online: http://www.real-statistics.com/one-way-analysisof-variance-anova/homogeneity-variances/levenes-test (accessed on 15 July 2016). 
33. Ho, R. Handbook of Univariate and Multivariate Data Analysis and Interpretation with SPSS, 1st ed.; Chapman and Hall/CRC: Boca Raton, FL, USA, 2006.

34. Speck, S.; Jilkova, J. Design of Environmental Tax Reforms in Europe. In Carbon Energy Taxation: Lessons from Europe; Andersen, M.S., Ekins, P., Eds.; Oxford University Press: Oxford, UK, 2009.

35. Jeffrey, C.; Perkins, J.D. The association between energy taxation, participation in an emissions trading system, and the intensity of carbon dioxide emissions in the European Union. Int. J. Account. 2015, 50, 397-417. [CrossRef]

36. Dusmanescu, D.; Andrei, J.; Popescu, G.H.; Nica, E.; Panait, M. Heuristic methodology for estimating the liquid biofuel potential of a region. Energies 2016, 9, 703. [CrossRef]

(C) 2017 by the authors. Licensee MDPI, Basel, Switzerland. This article is an open access article distributed under the terms and conditions of the Creative Commons Attribution (CC BY) license (http://creativecommons.org/licenses/by/4.0/). 